\title{
(2) OPEN ACCESS \\ Effect of spontaneous breathing on umbilical venous blood flow and placental transfusion during delayed cord clamping in preterm lambs
}

\author{
Emma Brouwer, ${ }^{1}$ Arjan B te Pas, ${ }^{1}$ Graeme R Polglase, ${ }^{2,3}$ Erin V McGillick, ${ }^{2,3}$ \\ Stefan Böhringer, ${ }^{4}$ Kelly J Crossley, ${ }^{2,3}$ Karyn Rodgers, ${ }^{2}$ Douglas Blank, ${ }^{5,6}$ \\ Shigeo Yamaoka, ${ }^{2}$ Andrew William Gill $0{ }^{7}{ }^{7}$ Martin Kluckow, ${ }^{8}$ Stuart B Hooper ${ }^{2,9}$
}

${ }^{1}$ Neonatology, LUMC, Leiden, The Netherlands

${ }^{2}$ The Ritchie Centre, The Hudson Institute for Medical Research, Clayton, Victoria, Australia ${ }^{3}$ Obstetrics and Gynaecology, Monash University, Clayton,

Victoria, Australia

${ }^{4}$ Biomedical Data Sciences LUMC, Leiden, The Netherlands ${ }^{5}$ Newborn Research, Royal Women's Hospital, Melbourne, Victoria, Australia

${ }^{6}$ The Ritchie Centre, Monash Institute of Medical Research, Monash University, Clayton,

Victoria, Australia

${ }^{7}$ Centre for Neonatal Research and Education, University of Western Australia, Perth, Western Australia, Australia ${ }^{8}$ Department of Neonatology, St Leonards, New South Wales, Australia

Obstetrics and Gynaecology, Monash University, Victoria, Australia

\section{Correspondence to} Professor Stuart B Hooper, Obstetrics and Gynaecology, Monash University, Clayton, VIC 3800, Australia;

stuart.hooper@monash.edu

Received 14 August 2018 Revised 4 March 2019 Accepted 2 April 2019 Published Online First 15 May 2019

\begin{abstract}
Introduction During delayed umbilical cord clamping, the factors underpinning placental transfusion remain unknown. We hypothesised that reductions in thoracic pressure during inspiration would enhance placental transfusion in spontaneously breathing preterm lambs. Objective Investigate the effect of spontaneous breathing on umbilical venous flow and body weight in preterm lambs.

Methods Pregnant sheep were instrumented at 132-133 days gestational age to measure fetal common umbilical venous, pulmonary and cerebral blood flows as well as arterial and intrapleural (IP) pressures. At delivery, doxapram and caffeine were administered to promote breathing. Lamb body weights were measured continuously and breathing was assessed by IP pressure changes.
\end{abstract}

Results In 6 lambs, 491 out of 1117 breaths were analysed for change in body weight. Weight increased in $46.6 \%$ and decreased in $47.5 \%$ of breaths. An overall mean increase of $0.02 \pm 2.5 \mathrm{~g}$ per breath was calculated, and no net placental transfusion was observed prior to cord clamping (median difference in body weight $52.3[-54.9-166.1] \mathrm{g}, \mathrm{p}=0.418)$. Umbilical venous (UV) flow transiently decreased with each inspiration, and in some cases ceased, before UV flow normalised during expiration. The reduction in UV flow was positively correlated with the standardised reduction in (IP) pressure, increasing by $109 \mathrm{~mL} / \mathrm{min}$ for every SD reduction in IP pressure. Thus, the reduction in UV flow was closely related to inspiratory depth.

Conclusions Spontaneous breathing had no net effect on body weight in preterm lambs at birth. UV blood flow decreased as inspiratory effort increased, possibly due to constriction of the inferior vena cava caused by diaphragmatic contraction, as previously observed in human fetuses.

Check for updates

(c) Author(s) (or their employer(s)) 2020. Re-use permitted under CC BY-NC. No commercial re-use. See rights and permissions. Published by BMJ.

To cite: Brouwer $\mathrm{E}$, te Pas $A B$, Polglase GR, et al. Arch Dis Child Fetal Neonatal Ed 2020:105:F26-F32.

\section{INTRODUCTION}

Placental to infant blood transfusion during delayed umbilical cord clamping (DCC) after birth $^{1}$ is evidenced by an increase in birth weight and a decrease in placental blood volume $e^{2-4}$ and is thought to occur at $2-3 \mathrm{~mL} / \mathrm{kg} / \mathrm{min}$ over the first 3 min after delivery. ${ }^{5}$ Animal studies have also shown that DCC until after ventilation onset prevents the reduction in cardiac output caused by immediate cord clamping (ICC). ${ }^{6}$ This finding has led to the

\section{What is already known on this topic?}

Delaying cord clamping until after the onset of ventilation improves pulmonary and cardiovascular haemodynamic stability in animal studies.

- The physiology underpinning the net movement of blood from the placenta to infant during delayed cord clamping remains unclear.

\section{What this study adds?}

- Umbilical venous blood flow reduces or ceases during inspiration and is correlated with the depth of the inspiration.

- Increases in intrathoracic pressure reduce or reverse umbilical venous blood flow, resulting in blood flowing out of the lamb.

- Spontaneous breathing did not result in net placental transfusion in preterm lambs.

concept that cord clamping should be based on the infant's physiology (ie, whether it is breathing) rather than on 'time after birth', which can be unrelated to the infant's physiological state. ${ }^{7-10}$ This concept is termed 'physiological-based cord clamping (PBCC)' and highlights the importance of pulmonary ventilation in mediating the benefits of DCC. ${ }^{11-13}$

In term newborns, DCC increases haemoglobin and ferritin levels, reduces rates of iron deficiency and anaemia in the first year of life. ${ }^{14}$ In preterm infants, small randomised trials have shown that DCC is associated with less intraventricular haemorrhage, necrotising enterocolitis, sepsis and need for blood transfusions, which are common complications associated with preterm birth. ${ }^{15-17}$ As a result, WHO now recommends DDC for $>60 \mathrm{~s}$ in infants not requiring resuscitation.

While placental transfusion is an accepted feature of DCC, little is known about the physiology causing the net movement of blood from the placenta into the infant during DCC. Most commentaries suggest that placental transfusion results from gravity (ie, when the infant is placed below the mother) or from uterine contractions squeezing blood out of the placenta into the infant. ${ }^{18}$ However, recent 
clinical trials in humans and animal experiments have failed to demonstrate an effect of gravity or uterine contractions on placental transfusion. ${ }^{4}{ }^{19}$ In a unique observational study in normal term infants, Doppler ultrasound was used to investigate blood flow patterns in both the umbilical artery and vein during DCC. $^{20}$ This study showed that umbilical venous (UV) flow was heavily influenced by breathing and crying. During inspiration, umbilical venous flow appeared to increase, whereas between breaths it appeared to cease. Similarly, umbilical artery flow was influenced by breathing and crying and at times was bidirectional, which was thought to result from uterine contractions. ${ }^{20}$

Animal experiments investigating the mechanisms of placental transfusion have consistently failed to detect a shift in blood volume from the placenta into the newborn. ${ }^{9} 19$ Possible explanations for this relate to the animal models used, which have mostly involved lambs delivered by caesarean section, followed by mechanical ventilation. ${ }^{9}{ }^{19}$ In this situation, intermittent increases in intrathoracic pressure combined with end-expiratory pressures may restrict net placenta-to-infant blood transfusion. In contrast, all human studies showing placental transfusion have been in vaginally delivered spontaneously breathing infants. ${ }^{21}$ In this study, we hypothesised that the subatmospheric (negative) intrathoracic pressure created during inspiration would enhance UV flow into the newborn, leading to a net increase in weight.

\section{METHODS}

All experimental procedures were conducted in accordance with the National Health and Medical Research Council code of practice for the care and use of animals for scientific purposes.

\section{Fetal surgery}

Sterile fetal surgery was performed on six pregnant ewes (Merino X Border Leicester) at 131-132 days (term is 147 days; 131-134 days is considered late preterm) of gestational age, 3 days prior to delivery. ${ }^{22}$ Briefly, anaesthesia was induced using an intravenous bolus of sodium thiopentane $(20 \mathrm{~mL}$ at $50 \mathrm{mg} / \mathrm{mL})$ and maintained following intubation by inhalation of isoflurane (1\%-3\% Isoflow, Abbot, Australia) in air/oxygen. Antibiotics (cefazoline, $1 \mathrm{~g} / 5 \mathrm{~mL}$ ) were administered before surgery. The fetal head, neck and abdomen were exteriorised via hysterotomy and jugular vein and carotid artery catheters inserted. Ultrasonic flow probes (Transonic Systems, Ithaca, New York, USA) were placed around the left pulmonary artery, common umbilical vein and right carotid artery. In lambs, the two umbilical veins within the cord join at the umbilicus to form the intraabdominal common umbilical vein before it enters the fetal liver and divides into the ductus venous or joins the hepatic portal system. A sterile, saline-filled intrapleural (IP) balloon catheter was also inserted into the IP space to measure changes in IP pressure during breathing. Following instrumentation, the fetus was returned to the amniotic sac and both catheters and flow-probe leads were exteriorised via the ewe's right flank for continuous monitoring until delivery, 3 days later. During the postoperative period, ewes received analgesia via a fentanyl patch $(75 \mu \mathrm{g} /$ hour $)$ and daily antibiotics $(2.5 \mathrm{~mL}$ cefazoline $1 \mathrm{~g} / 5 \mathrm{~mL})$.

\section{Experimental protocol}

Prior to delivery, electronic recordings of blood flows in the left pulmonary artery, umbilical vein and right carotid artery as well as pressures in the carotid artery and IP space commenced using a data acquisition system (Powerlab ADI, Sydney, Australia). As general anaesthesia is known to inhibit spontaneous breathing activity, lambs were delivered under spinal anaesthesia at 133-134 days of gestations. Ewes were sedated with $10 \mathrm{~mL}$ propofol $1 \%(10 \mathrm{mg} / \mathrm{mL})$ to administer spinal anaesthesia (lignocain 2\%, $0.1 \mathrm{~mL} / \mathrm{kg}$ ) via the sacral lumbar space. Following successful induction of spinal anaesthesia, mild sedation of the ewe continued using midazolam $(1.0 \mathrm{mg} / \mathrm{kg} / \mathrm{hour}$ at $20-25 \mathrm{~mL} /$ hour). The fetal head and neck were exteriorised via caesarean section and the lambs were intubated using an endotracheal tube ( $4.5 \mathrm{~mm}$ cuffed endotracheal tube). Lambs were intubated as the application of facemask without leak is problematic and, in addition intubation ensured opening of the larynx. A transcutaneous oxygen saturation probe (Masimo, Radical 7, California, USA) was placed around the right foreleg, a near-infrared spectroscopy (NIRS) optode (Casmed Foresight, CAS Medical Systems, Branford, Connecticut, USA) was placed over the left frontal cortex, and a rectal temperature probe was inserted and used to correct blood gas measurements. The lamb was dried and placed on electronic scales (Bilanciai D70, Campogalliano, Italy) immediately beside the ewe, taking care to avoid stretching or mechanically interfering with the umbilical cord; the lamb's weight was recorded continuously. Lambs were given naloxone ( $400 \mu \mathrm{g}$ intravenous) and Anexate ( $0.04 \mathrm{mg}$ bolus intravenous) to counter the inhibitory effects of fentanyl (postoperative analgesia of the ewe) and midazolam (maternal sedation), respectively, on respiration. They were also given caffeine $(20 \mathrm{mg} / \mathrm{kg}$ loading dose and $10 \mathrm{mg} / \mathrm{kg} / \mathrm{hour})$ and doxapram $(5 \mathrm{mg} / \mathrm{kg}$ loading dose and $2.5 \mathrm{mg} / \mathrm{kg} / \mathrm{hour}$ ) to stimulate breathing.

If the lamb was breathing spontaneously, it was given continuous positive airway pressure $\left(5 \mathrm{cmH}_{2} \mathrm{O}\right)$ via endotracheal tube ( $4.5 \mathrm{~mm}$ cuffed endotracheal tube) and disturbed as little as possible to avoid affecting the body weight recordings and other physiological measurements. If the lamb did not initiate spontaneous breathing following delivery and physical stimulation, a sustained inflation (SI) was administered (peak inspiratory pressure [PIP] of $35 \mathrm{cmH}_{2} \mathrm{O}$ for $30 \mathrm{~s}$ ). Following the SI, if spontaneous breathing did not commence or if the lambs became apnoeic, brief periods of intermittent positive pressure ventilation (PIP of $35 \mathrm{cmH}_{2} \mathrm{O}$ with a positive end expiratory pressure (PEEP) of $5 \mathrm{cmH}_{2} \mathrm{O}$ ) was applied to avoid hypoxia. During the experiment, no supplemental oxygen was administered to the lamb as it was still receiving oxygenation from the ewe via the umbilical cord. All physiological parameters were recorded continuously throughout the experiment. Umbilical cord clamping occurred once the lamb was assessed to have established a stable breathing pattern and the pulmonary blood flow (PBF) waveform had adopted the neonatal phenotype (figure 1); this took up to $19: 15$ (15:55-20:25) min postdelivery to achieve in our experiments.

Following cord clamping, the lamb was placed under a radiant heater and was ventilated using a Babylog 8000+ ventilator (Dräger, Lübeck, Germany) with a PEEP of $5 \mathrm{cmH}_{2} \mathrm{O}$ for an additional $30 \mathrm{~min}$. All physiological recordings commenced prior to, or at delivery (NIRS, oxygen saturation $\left[\mathrm{SpO}_{2}\right]$, weight) and arterial blood gasses were taken at regular intervals following delivery to assess lamb well-being. All blood samples and liquid volumes taken or given to the lamb while they were being weighed were recorded to adjust the weight measurements.

The ewe was euthanised following cord clamping, using an overdose of pentobarbitone $(100 \mathrm{mg} / \mathrm{kg}$ intravenous). Lambs were euthanised after completion of the ventilation period using an overdose of pentobarbitone administered intravenously. Lamb body and organ weights were recorded postmortem. 


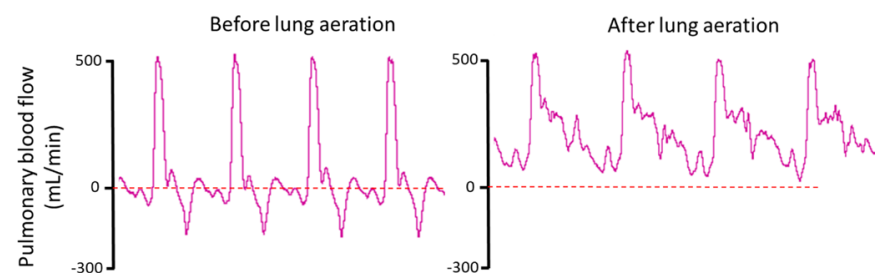

Figure 1 Pulmonary blood flow (PBF) wave form before and after lung aeration. Physiological recordings of instantaneous PBF measured throughout four consecutive cardiac cycles before and after lung aeration. Before lung aeration, the PBF wave form is characterised by a positive, narrow systolic peak followed by retrograde (negative value) flow throughout most of diastole. This blood flows retrogradely out of the pulmonary circulation and across the ductus arteriosus (DA) into the dorsal aorta, resulting in continuous right-to-left shunting in the DA throughout the cardiac cycle. After transition, the systolic peak is broader and flow continues into the lung throughout the cardiac cycle. The continuous forward flow into the lungs during diastole results from a reversal in the pressure gradient between the pulmonary and systemic circulations resulting in left-to-right shunting through the DA.

\section{Analytical methods}

Recordings of physiological measurements made prior to, during and after delivery were analysed using LabChart 8 (ADInstruments). A breath-by-breath analysis, which involved analysing every individual spontaneous breath in all animals, was performed to observe the effect of breathing on weight and UV flow. All breathing events were annotated manually by the researcher (EB) to determine change in lamb weight, IP pressure and UV flow with each spontaneous breath. To make IP pressure comparable across animals, measurements were standardised per individual (mean was subtracted and values were divided by the SD). The basal IP pressure is a relative measure that varies between animals, whereas the change in IP pressure from baseline is a precise measurement. Standardised values per animal allows interpretation of the data in terms of quantiles, for example, a value of 2 corresponds to the $97.5 \%$ quantile of IP measurements within this animal. Analysis of carotid arterial (CA) pressure, CA blood flow and PBF, involved averaging values over five consecutive heartbeats for each time point.

\section{Statistical analysis}

Statistical analysis was performed using IBM SPSS Statistics V.24.0. Data on CA pressure, CA blood flow, PBF, UV flow and temperature are presented as median and IQR. Paired t-test was used to compare weight measurements at delivery with weight measurements prior to cord clamping. A linear regression analysis was used to determine the effect of breathing on UV flow and weight in separate analyses. Animal ID were added as fixed factor to each model to account for clustering of measurements within animals.
A
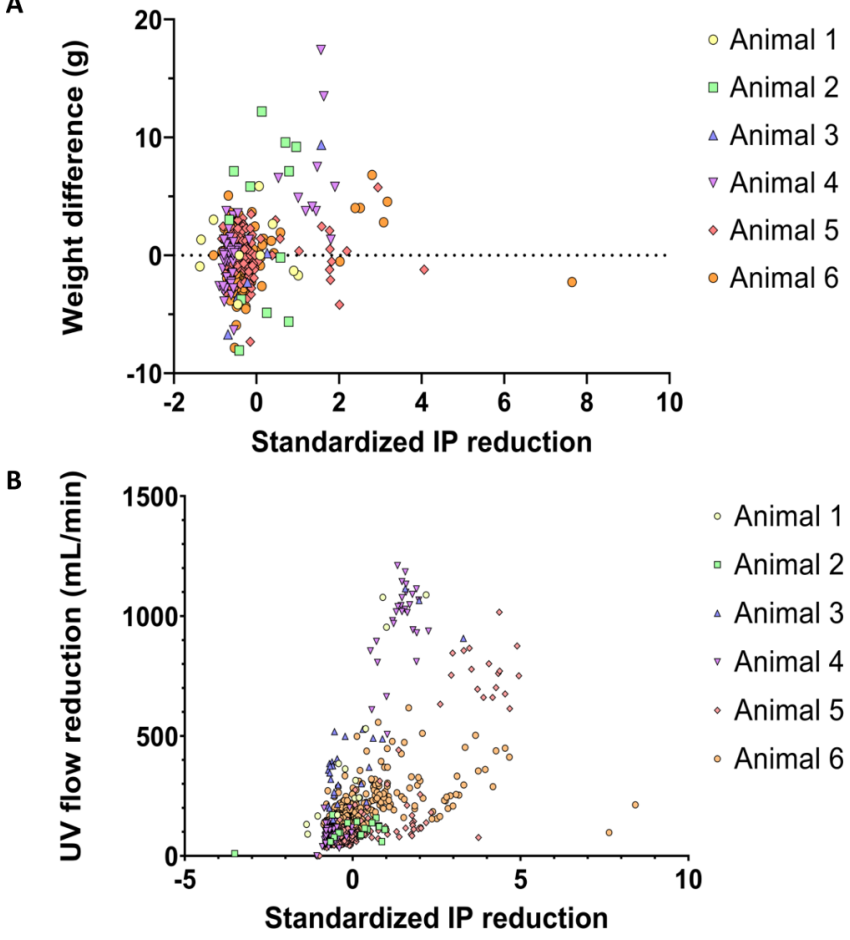

Figure 2 Relationship between intrapleural (IP) pressure and body weight change and common umbilical venous (UV) blood flow per breath. (A) A relationship was observed between the depth of inspiration and body weight change detected with each breath. Body weight increased in $46.6 \%$ of breaths and decreased in $47.5 \%$ of breaths. Total mean increase in body weight per breath was $0.02 \mathrm{~g}$. (B) The depth of inspiration, as indicated by the reduction in IP pressure was positively correlated with the decrease in UV blood flow before umbilical cord clamping.

A p value $\leq 0.05$ was considered to be statistically significant. A sensitivity analysis was performed for the relationships between the reduction in IP pressure and both UV flow and weight by excluding the animal with the largest number of measurements. These analyses (data not shown) were performed to exclude the possibility that measurements from a single animal dominated the results. As the results were very similar to the analysis with the complete data, the outcomes were not influenced by the number of measurements from any one animal.

\section{RESULTS}

Fetal characteristics and blood gas status at the beginning of experiments are displayed in table 1 . One out of the six lambs was male.

\section{Effect of spontaneous breaths on lamb weight}

The breath-by-breath analysis evaluated 1117 breaths, which resulted in an average reduction of IP pressure of $8.6 \pm 0.3 \mathrm{~mm} \mathrm{Hg}$

Table 1 Fetal characteristics

\begin{tabular}{llccc}
\hline $\mathbf{n}=6$ & Fetal & 5 min prior to cord clamping & 5 min after cord clamping & 10 min after cord clamping \\
\hline Gestational age (days) & $134(134-134)$ & - & - & - \\
$\mathrm{pH}$ & $7.39(7.37-7.42)$ & $7.27(7.27-)$ & $7.13(7.12-7.22)$ & $7.12(7.07-7.24)$ \\
$\mathrm{pCO}_{2}$ & $45.6(44.6-49)$ & $54.2(44.9-)$ & $70.2(64.4-73.3)$ & $72.1(52.5-85.8)$ \\
$\mathrm{pO}_{2}$ & $23.6(21.2-27.1)$ & $35.1(32.9-)$ & $42.4(22.7-51.7)$ & $74.0(47.0-96.1)$ \\
Saturation (\%) & $69.4(58.9-72.3)$ & $82(74.9-)$ & $84.4(50.5-90.9)$ & $96.8(74.5-98.1)$ \\
\hline
\end{tabular}

Characteristics displayed as median (IQR). 


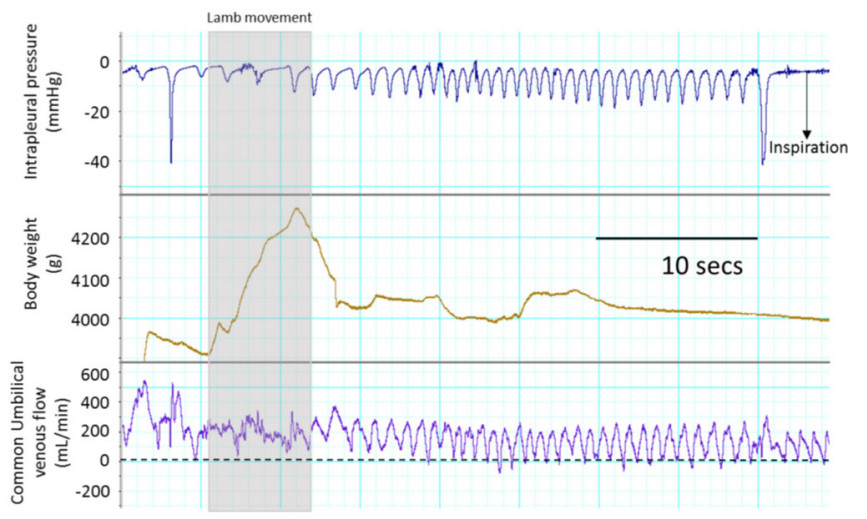

Figure 3 Physiological recordings of intrapleural (IP) pressure, body weight and common umbilical venous (UV) blood flow. Changes in IP pressure, body weight and UV blood flow before umbilical cord clamping. Transient reductions in IP pressure occur in response to inspiration which are closely associated with transient reductions in, or cessations of, UV blood flow. No changes in lamb weight were associated with individual breaths or an entire period of spontaneous breathing.

(range 2.2-72.2 $\mathrm{mm} \mathrm{Hg}$ ); this equates to a mean reduction in pressure of $11.2 \pm 0.6 \mathrm{cmH}_{2} \mathrm{O}$ (range $2.9-93.8 \mathrm{cmH}_{2} \mathrm{O}$ ). Of the 1117 breaths analysed, 626 breaths were excluded from weight analysis due to major weight changes caused by artefacts such as body movement. Of the 491 breaths analysed for weight, $46.6 \%$ of breaths were associated with an increase in weight, 5.9\% were associated with no change in weight and $47.5 \%$ of breaths were associated with a decrease in weight. Overall, the mean increase in lamb weight per breath was $0.02 \pm 2.5 \mathrm{~g}$ (figure $2 \mathrm{~A}$ ). The increase in weight was positively correlated with the standardised reduction in IP pressure. The regression coefficient was 0.839 meaning that for an IP pressure that is $1 \mathrm{SD}$ above the mean, weight increased by $0.839 \mathrm{~g}$. Median (IQR) lamb body weight was 3969 (3635-4131) g at delivery, 3924 (3668-4080) g

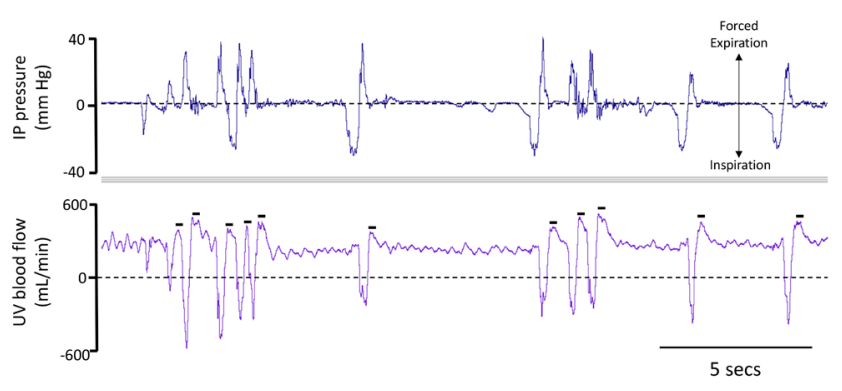

Figure 4 Physiological recordings of intrapleural (IP) pressure and common umbilical venous (UV) blood flow. Changes in IP pressure and UV blood flow in a spontaneously breathing lamb displaying a forced expiration (transient increase in IP pressure) following each inspiration (transient decrease in IP pressure). While transient reductions in IP pressure associated with inspiration caused reduction/cessation of UV blood flow, increases in IP pressure associated with abdominal contractions also caused a reduction in UV blood flow. Indeed, increases in IP pressure were closely associated with a reversal in UV blood flow, causing blood to flow away from the lamb and pool up stream in either the cord or placenta. As a result, following restoration of IP pressure, UV blood flow transiently increased above baseline (indicate by small black bars). at $10 \mathrm{~min}$ before cord clamping and 4038 (3610-4201) g at time of cord clamping. No net placental transfusion was measured or observed during spontaneous breathing prior to cord clamping as measured by body weight change $(\mathrm{p}=0.418)$.

\section{Common umbilical venous flow}

In $44 \%$ of the breaths analysed, blood flow in the common UV transiently $(0.31 \pm 0.19 \mathrm{~s}$ in duration) decreased with inspiration (figures 3 and 4); the delay between peak reduction in IP pressure and peak reduction in UV flow varied between 120 and $300 \mathrm{~ms}$. The mean reduction in common UV flow per breath was $183.4 \pm 4.5 \mathrm{~mL} / \mathrm{min}$ (range $79.4-627.8 \mathrm{~mL} / \mathrm{min}$ ). Reductions in UV flow that decreased below zero were also commonly observed, indicating that flow in the common UV had reversed (indicated by negative blood flow value) and transiently flowed back towards the placenta (figure 4). These reversals in flows were most often associated with large inspiratory efforts that were immediately followed by transient increases in IP pressure. Following these reversals in flow, common UV flow transiently increased above baseline values following the restoration in IP pressure. Reductions in UV flow that often resulted in a reversal of common UV flow, also occurred during transient increases in IP pressure that were not preceded by inspiration (figure 4); this was relatively common in all lambs.

The reduction in common UV flow was found to be positively correlated with the standardised reduction in IP pressure. The regression coefficient was 109.0 and as such, a 1 SD reduction in IP pressure below the mean basal value will reduce UV flow by $109.0 \mathrm{~mL} / \mathrm{min}$ (figure $2 \mathrm{~B}$ ). Thus, as the depth of the inspiration increased, the associated reduction in common UV flow increased, causing flow to cease or even reverse with some breaths (figures 3 and 4).

\section{Haemodynamics}

\section{Carotid arterial pressure and flow}

Following delivery and ventilation onset, mean CA pressure and blood flow remained relatively constant for the 10 min leading up to cord clamping. Immediately following cord clamping, CA pressure (by $\sim 0.5 \mathrm{~mm} \mathrm{Hg}$ ) slightly increased. While CA pressure remained relatively constant, CA flow gradually increased, reaching a maximum of $86 \mathrm{~mL} / \mathrm{min}$ at $8 \mathrm{~min}$ following cord clamping (table 2).

\section{Pulmonary artery blood flow}

At 10 min prior to cord clamping, PBF was quite variable (table 2) between lambs, with some lambs having already aerated their lungs and transitioned their pulmonary circulation (as indicated by PBF wave form; figure 1), whereas others still had a predominantly fetal PBF waveform phenotype. Immediately following cord clamping, PBF increased and tended to increase further over the subsequent $10 \mathrm{~min}$ following umbilical cord clamping.

\section{DISCUSSION}

International resuscitation guidelines currently recommend DCC for $60 \mathrm{~s}$ in infants who do not need resuscitation, largely based on the concept of placental to infant blood transfusion. ${ }^{23}{ }^{24}$ While previous studies have shown a beneficial effect of DCC on neonatal outcomes, ${ }^{14} 21$ the physiological mechanisms underpinning the net shift of blood from the placenta into the infant during DCC remains unknown. We consider that a better understanding of this physiology and the factors influencing placental transfusion could help optimise the practice of DCC in the delivery room. We hypothesised that the reduction in 


\begin{tabular}{lllll}
\hline \multicolumn{1}{l}{ Table 2} & Averaged measurements in the 10 min prior to and 10 min after cord clamping & & \\
\hline Time $(\mathbf{m i n})$ & CA pressure $(\mathrm{mm} \mathrm{Hg})$ & CA flow $(\mathrm{mL} / \mathrm{min})$ & PA flow (mL/min) & Body temperature \\
\hline-10 & $48.73(40.37-56.11)$ & $60.35(43.10-83.63)$ & $137.82(62.22-254.00)$ & $39.5(39.0-39.8)$ \\
-5 & $50.32(46.94-58.39)$ & $43.32(27.25-61.75)$ & $240.53(138.00-298.67)$ & $38.6(37.7-39.5)$ \\
-2 & $48.02(41.16-55.40)$ & $42.33(32.94-57.20)$ & $312.64(179.14-403.90)$ & $38.2(37.4-38.9)$ \\
\hline Cord clamped $(\mathbf{m i n})$ & $54.45(49.03-61.00)$ & $49.27(40.37-62.33)$ & $354.40(224.28-457.53)$ & $38.2(37.8-38.8)$ \\
1 & $54.98(50.06-62.14)$ & $52.15(46.46-73.45)$ & $255.87(218.88-422.99)$ & $38.2(37.8-38.7)$ \\
2 & $58.96(47.83-65.98)$ & $58.14(50.32-86.52)$ & $314.78(218-462.60)$ & $38.05(37.2-38.4)$ \\
3 & $55.51(50.16-64.59)$ & $62.65(47.64-92.08)$ & $281.72(224.34-446.64)$ & $38.1(37.8-38.4)$ \\
4 & $58.83(49.43-70.06)$ & $68.41(61.64-105.60)$ & $313.45(239.18-541.80)$ & $38.0(37.2-38.3)$ \\
5 & $59.97(48.41-69.04)$ & $73.61(61.91-92.85)$ & $319.15(217.48-449.91)$ & $38.0(37.5-38.6)$ \\
6 & $55.28(48.74-70.17)$ & $74.36(53.45-93.81)$ & $260.98(200.38-320.13)$ & $37.9(37.0-38.6)$ \\
7 & $58.27(49.60-74.29)$ & $82.93(69.51-126.51)$ & $389.07(268.02-463.93)$ & $36.7(35.7-38.5)$ \\
8 & $55.30(47.03-79.75)$ & $85.66(64.12-106.34)$ & $343.40(280.24-437.31)$ & $37.8(37.4-38.6)$ \\
9 & $71.65(48.77-75.96)$ & $71.93(59.60-102.05)$ & $356.79(286.36-600.84)$ & $38.1(37.2-38.7)$ \\
\hline
\end{tabular}

CA pressure, CA flow and PA flow are displayed as median (IQR), $10 \mathrm{~min}$ before and $10 \mathrm{~min}$ after cord clamping. CA pressure increases after cord clamping with $\sim 4 \mathrm{~mm} \mathrm{Hg}$ at $4 \mathrm{~min}$, after which it remains stable. CA flow increases up to $8 \mathrm{~min}$ with $\sim 36 \mathrm{~mL} / \mathrm{min}$. PA flow increases with a maximum of $35 \mathrm{~mL} / \mathrm{min}$ after cord clamping. Temperature decreases with $0.2^{\circ} \mathrm{C}$.

$\mathrm{CA}$, carotid arterial; PA, pulmonary artery.

intrathoracic pressure associated with inspiration would provide a pressure gradient favouring blood flow from the placenta into the infant and restrict flow in the opposite direction. However, contrary to our hypothesis, we found that UV flow into newborn lambs transiently reduced, ceased or even reversed during individual breaths, depending on the respiratory pattern, and that the reduction in flow was positively correlated with the depth of the inspiration. It is not surprising, therefore, we also did not observe a relationship between spontaneous breathing and net weight gain of the lamb.

Evidence for placental transfusion in humans is well established ${ }^{5}$ and includes an increase in infant weight during DCC, an increase in neonatal blood volume and a decrease in blood volume remaining within the placenta after DCC. ${ }^{1252526}$ However, our previous animal studies have been unable to provide any evidence of placental transfusion, which we considered was due to the absence of spontaneous breathing; instead all lambs were mechanically ventilated. ${ }^{9}{ }^{19}$ As such, in this study we aimed to investigate whether subatmospheric pressures generated during inspiration resulted in placental transfusion. To measure placental transfusion, lamb body weights and UV flows were measured continuously throughout a period of DCC. However, the body weight measurements proved to be challenging as any slight movement or touching of the lamb caused large rapid changes in measured weight that were artefactual and unrelated to body weight changes; these sections of physiological recordings were manually detected and excluded from analysis. To counter the inhibitory effects of maternal sedation on spontaneous breathing, all lambs received drugs to reverse these effects and therefore body movements were common during the experiment, resulting in some unreliable weight measurements (figure 3). Nevertheless, even when the lambs were not moving and the weights were stable, we could not identify a relationship between breathing (IP) and weight change over an entire breathing episode (figure 2A). Nevertheless, the linear regression analysis detected a relationship between the standardised IP reduction and a very small increase in weight. Considering that the UV flow was markedly reduced with each breath (see below), it is difficult to explain how this might occur. However, the effect of individual breaths on weight change are transient, reversed at the end of the breath and may involve a transient discrepancy between UV flow into and UA flow out of the lamb.

Although we found that UV flow was influenced by spontaneous breathing and the associated decrease in IP pressure, the relationship was opposite to what we hypothesised. We hypothesised that the decrease in intrathoracic pressure associated with inspiration would provide a pressure gradient to increase UV flow into the lamb. However, we found that UV flow transiently decreased during inspiration, commonly decreasing to zero at end-inspiration. Furthermore, we found a strong positive relationship between the degree of decrease in UV flow and the size of the reduction in intrathoracic pressure generated by inspiration (figure $2 \mathrm{~B}$ ). While we were initially surprised by this finding, it is consistent with previously described findings measured by ultrasound in human fetuses during periods of fetal breathing movements (FBM). ${ }^{27}$ This study showed that during inspiration, contraction of the diaphragm causes narrowing and closure of the inferior vena cava (IVC) as it passes through the diaphragm, causing IVC flow to cease. Blood returning from the UV, either via the ductus venosus or hepatic veins, also has to pass through the diaphragm via the same orifice as the IVC. As such, it is likely that the ductus venosus constricts along with the IVC as the diaphragm contracts, causing blood flow in the UV to cease during inspiration. Due to the large compliance of the low pressure venous system, it is highly likely that these reductions in flow are slightly delayed in relation to the timing of inspiration. We found the delay to be $120-300 \mathrm{~ms}$ in the intra-abdominal common UV, but this delay is likely to be larger when measured further upstream, closer to the placenta. As a result, when measured upstream in the cord, depending on the breathing rate, the reductions in UV flow may be completely out of synchrony with breathing. This finding explains why increases in UV flow appeared to be related to inspiration, whereas cessations in UV flow appeared to be related to expiration, in our previous study in human infants; in that study UV flows were measured upstream in the cord. ${ }^{20}$ Nevertheless, the findings convincingly demonstrate that large subatmospheric reductions in intrathoracic pressure cannot account for placental transfusion.

As noted in figure 3, both increases in IP pressure by itself, or following a large inspiratory effort, can result in a transient 
reversal of blood flow in the common UV, pushing blood back out of the lamb towards the placenta. These increases in IP pressure were undoubtedly due to abdominal muscle contractions that must also have resulted in large increases in intraabdominal pressure. In the physiological recording displayed in figure 3, each inspiratory effort is immediately followed by a forced expiratory effort, as indicated by a large increase in IP pressure (up to $40 \mathrm{~mm} \mathrm{Hg}$ ), which must have been driven by abdominal muscle contractions. In addition, a reversal in UV flow was also observed when transient increases in IP pressure were not preceded by inspiration. The precise reasons for these are unclear, but abdominal muscle contractions associated with grunting or body movements are possible explanations. Nevertheless, whether or not the increases in intrathoracic (and abdominal) pressure are associated with breathing, they are associated with a transient reversal in UV flow. This finding is not surprising given that the IP pressure increase (up to $40 \mathrm{~mm} \mathrm{Hg}$; figure 3) is considerably larger than UV pressure in the cord. However, once the IP pressures begin to stabilise, UV blood flow transiently increases above baseline, which likely reflects a rebound increase in flow caused by blood pooling upstream in the cord and placenta (figure 3 ).

Ventilating the lung before clamping the umbilical cord, also known as PBCC, is known to promote haemodynamic stability immediately after birth. ${ }^{628}$ In particular, it avoids the large rapid increase in blood pressure caused by increasing systemic vascular resistance when the cord is clamped and the reduction in cardiac output caused by the loss of umbilical venous return and ventricular preload. ${ }^{10}$ Avoiding these significant cardiovascular events is likely to be a major contributing factor to the reduction in neonatal morbidities, such as intraventricular haemorrhage, associated with DCC. ${ }^{6}$ We found that CA pressure increased slightly following umbilical cord clamping (by $\sim 0.5 \mathrm{~mm} \mathrm{Hg}$ ), but this increase is substantially less than the increase that occurs with cord clamping before ventilation/breathing onset $(\sim 20 \mathrm{~mm} \mathrm{Hg}){ }^{6}$ While the CA pressure tended to increase over the subsequent 9 min (by $\sim 15 \mathrm{~mm} \mathrm{Hg}$ ), this increase appeared more to do with the lamb's activity levels than to cord clamping. Similarly, CA blood flow increased over the same time frame (by $30 \mathrm{~mL} / \mathrm{min}$ ), which indicates that cardiac output was sustained throughout the cord clamping period. PBF doubled in the minutes leading up to cord clamping, which was expected as it is well established that the increase in PBF after birth is triggered by lung aeration resulting from breathing onset. ${ }^{29} 30$ Although PBF tended to increase in response to cord clamping, before cord clamping the majority of right ventricular output was mainly directed through the lungs rather than across the ductus arteriosus. This is clearly indicated by the PBF wave form (figure 1), whereby after transition, forward flow into the lung occurs throughout the cardiac cycle. Forward flow into the lung during diastole results from a reversal of flow through the ductus arteriosus due to the reduction in PVR causing a reversal in the pressure gradient between systemic and pulmonary circulations. ${ }^{22}$ As clamping of the umbilical cord increases systemic arterial pressure, the increase in PBF following cord clamping likely results from increased leftto-right shunting of blood through the ductus arteriosus during diastole. These results are consistent with our previous findings in ventilated lambs. ${ }^{6}$ Taken together, these results clearly demonstrate a haemodynamically stable transition when lung aeration precedes cord clamping, irrespective of whether the lambs were ventilated or breathed spontaneously.

Temperature measurements stayed stable throughout the experiments, with the median temperature varying between $36.7^{\circ} \mathrm{C}$ and $39.5^{\circ} \mathrm{C}\left(39.0^{\circ} \mathrm{C}\right.$ is the normal core body temperature in fetal sheep). Before cord clamping, the external application of heat required to maintain lamb body temperature was minimal and restricted to one hot water bottle and a wrap. However, after cord clamping an overhead radiant heater, two hot water bottles and a wrap were needed to maintain a stable temperature. While anecdotal, this indicates that when the cord is intact, umbilical blood flow may provide an effective source of heat that helps to maintain body temperature. While some heat loss may occur over the length of the umbilical cord, presumably this was compensated for by the continuous flow of blood flowing through the umbilical vessels at the ewe's body temperature.

\section{CONCLUSION}

In summary, contrary to our hypothesis, we found that during inspiration, UV flow was either reduced or ceased depending on the size of the inspiration. This finding was likely caused by narrowing or closure of the IVC during contraction of the diaphragm during inspiration as previously described in human fetuses during FBM in utero. ${ }^{27}$ The reduction in UV flow was positively correlated with the depth of the inspiration. Increases in IP pressure, likely caused by abdominal contractions, also reduced UV flow and caused it to transiently reverse, resulting in blood flowing out of the lamb and pooling in the cord or placenta. This study confirms the previous results of Bhatt et $a l$, showing haemodynamic stability when ventilation onset precedes cord clamping and demonstrates that the mode of ventilation (spontaneous breathing vs mechanical ventilation) does not impact on this stability or on placental transfusion. ${ }^{6}$ Instead, the haemodynamic stability is reliant on the increase in PBF. Clearly, further research is required to understand the mechanisms responsible for placental transfusion.

Correction notice This paper has been updated since it was published Online First. Figures 3 and 4 were the same in the original manuscript and so figure 3 has now been updated.

Acknowledgements The authors would like to thank Valerie Zahra, Alison Moxham and Dalibor Stanojkovic for participating in surgery and the experiments.

Contributors $E B, A B t P, G R P, A W G, M K$ and $S B H$ were responsible for the conception and design of the experiments. EB, GRP, EVM, SB, KJC, KR, SY, DB, SBH were each involved in acquisition, analysis or interpretation of the data. $E B, A B t P$, SBH drafted the article and all coauthors have contributed to and approved the final version to be published.

Funding This research was supported by an NHMRC Programme Grant (APP 1113902) and the Victorian Government's Operational Infrastructure Support Programme. ABtP was the recipient of a Vidi grant, The Netherlands Organisation for Health Research and Development (ZonMw), part of the Innovational Research Incentives Scheme Veni-Vidi-Vici (NWO-Vidi 2015/2016). SBH was supported by an NHMRC Principal Research Fellowship (APP1058537).

Competing interests None declared.

Patient consent for publication Not required.

Ethics approval Monash University's Monash Medical Centre Animal Ethics Committee.

Provenance and peer review Not commissioned; externally peer reviewed.

Open access This is an open access article distributed in accordance with the Creative Commons Attribution Non Commercial (CC BY-NC 4.0) license, which permits others to distribute, remix, adapt, build upon this work non-commercially, and license their derivative works on different terms, provided the original work is properly cited, appropriate credit is given, any changes made indicated, and the use is non-commercial. See: http://creativecommons.org/licenses/by-nc/4.0/.

\section{ORCID iD}

Andrew William Gill http://orcid.org/0000-0003-0212-3103

\section{REFERENCES}

1 Yao AC, Hirvensalo M, Lind J. Placental transfusion-rate and uterine contraction. Lancet 1968;1:380-3. 
2 Law GR, Cattle B, Farrar D, et al. Placental blood transfusion in newborn babies reaches a plateau after $140 \mathrm{~s}$ : Further analysis of longitudinal survey of weight change. SAGE Open Med 2013;1:205031211350332.

3 Mercer JS, Erickson-Owens DA, Collins J, et al. Effects of delayed cord clamping on residual placental blood volume, hemoglobin and bilirubin levels in term infants: a randomized controlled trial. J Perinatol 2017;37:260-4.

4 Vain NE, Satragno DS, Gorenstein AN, et al. Effect of gravity on volume of placental transfusion: a multicentre, randomised, non-inferiority trial. Lancet 2014;384:235-40.

5 Yao AC, Moinian M, Lind J. Distribution of blood between infant and placenta after birth. Lancet 1969;2:871-3.

6 Bhatt S, Alison BJ, Wallace EM, et al. Delaying cord clamping until ventilation onset improves cardiovascular function at birth in preterm lambs. J Physiol 2013:591:2113-26

7 Polglase GR, Dawson JA, Kluckow M, et al. Ventilation onset prior to umbilical cord clamping (physiological-based cord clamping) improves systemic and cerebral oxygenation in preterm lambs. PLoS One 2015;10:e0117504.

8 Polglase GR, Blank DA, Barton SK, et al. Physiologically based cord clamping stabilises cardiac output and reduces cerebrovascular injury in asphyxiated near-term lambs. Arch Dis Child Fetal Neonatal Ed 2018;103:F530-F538.

9 Blank DA, Polglase GR, Kluckow M, et al. Haemodynamic effects of umbilical cord milking in premature sheep during the neonatal transition. Arch Dis Child Fetal Neonatal Ed 2018:103:F539-F546.

10 Hooper SB, Polglase GR, Roehr CC. Cardiopulmonary changes with aeration of the newborn lung. Paediatr Respir Rev 2015;16:147-50.

$11 \mathrm{Knol} \mathrm{R}$, Brouwer E, Vernooij ASN, et al. Clinical aspects of incorporating cord clamping into stabilisation of preterm infants. Arch Dis Child Fetal Neonatal Ed 2018;103:F49 3-F497.

12 Hooper SB, Polglase GR, te Pas AB. A physiological approach to the timing of umbilical cord clamping at birth. Arch Dis Child Fetal Neonatal Ed 2015;100:F355-F360.

13 Hooper SB, Binder-Heschl C, Polglase GR, et al. The timing of umbilical cord clamping at birth: physiological considerations. Matern Health Neonatol Perinatol 2016;2:4.

14 McDonald SJ, Middleton P, Dowswell T, et al. Effect of timing of umbilical cord clamping of term infants on maternal and neonatal outcomes. Evid Based Child Health 2014;9:303-97.

15 Rabe H, Reynolds G, Diaz-Rossello J. A systematic review and meta-analysis of a brief delay in clamping the umbilical cord of preterm infants. Neonatology 2008:93:138-44.
16 Fogarty M, Osborn DA, Askie L, et al. Delayed vs early umbilical cord clamping for preterm infants: a systematic review and meta-analysis. Am J Obstet Gynecol 2018;218:1-18.

17 Tarnow-Mordi W, Morris J, Kirby A, et al. Delayed versus Immediate Cord Clamping in Preterm Infants. N Engl J Med 2017;377:2445-55.

18 Yao AC, Lind J. Effect of gravity on placental transfusion. Lancet 1969:2:505-8.

19 Hooper SB, Crossley KJ, Zahra VA, et al. Effect of body position and ventilation on umbilical artery and venous blood flows during delayed umbilical cord clamping in preterm lambs. Arch Dis Child Fetal Neonatal Ed 2017;102:F312-F319.

20 Boere I, Roest AA, Wallace E, et al. Umbilical blood flow patterns directly after birth before delayed cord clamping. Arch Dis Child Fetal Neonatal Ed 2015;100:F12 $1-\mathrm{F} 125$.

21 Rabe H, Diaz-Rossello JL, Duley L, et al. Effect of timing of umbilical cord clamping and other strategies to influence placental transfusion at preterm birth on materna and infant outcomes. Cochrane Database Syst Rev 2012:8:Cd003248.

22 Crossley KJ, Allison BJ, Polglase GR, et al. Dynamic changes in the direction of blood flow through the ductus arteriosus at birth. J Physiol 2009;587(Pt 19):4695-704.

23 Wyckoff MH, Aziz K, Escobedo MB, et al. Part 13: Neonatal Resuscitation: 2015 American Heart Association Guidelines Update for Cardiopulmonary Resuscitation and Emergency Cardiovascular Care. Circulation 2015;132(18 Suppl 2):S543-60.

24 WHO Guidelines Approved by the Guidelines Review Committee. Guideline: Delayed Umbilical Cord Clamping for Improved Maternal and Infant Health and Nutrition Outcomes. Geneva: World Health Organization Copyright, 2014.

25 Jahazi A, Kordi M, Mirbehbahani NB, et al. The effect of early and late umbilical cord clamping on neonatal hematocrit. J Perinatol 2008;28:523-5.

26 Linderkamp 0 , Nelle M, Kraus $M$, et al. The effect of early and late cord-clamping on blood viscosity and other hemorheological parameters in full-term neonates. Acta Paediatr 1992:81:745-50.

27 Nyberg MK, Johnsen SL, Rasmussen S, et al. Hemodynamics of fetal breathing movements: the inferior vena cava. Ultrasound Obstet Gynecol 2011;38:658-64.

28 Brouwer E, Knol R, Vernooij ASN, et al. Physiological-based cord clamping in preterm infants using a new purpose-built resuscitation table: a feasibility study. Arch Dis Child Fetal Neonatal Ed 2019;104:F396-402.

29 Lang JA, Pearson JT, Binder-Heschl C, et al. Increase in pulmonary blood flow at birth: role of oxygen and lung aeration. J Physio/ 2016;594:1389-98.

30 Lang JA, Pearson JT, te Pas AB, et al. Ventilation/perfusion mismatch during lung aeration at birth. J App/ Physiol 2014:117:535-43. 